Claremont Colleges

Scholarship@ Claremont

Pitzer Faculty Publications and Research

Pitzer Faculty Scholarship

$1-1-2006$

\title{
A Very Little Bit of Knowledge: Re-Evaluating the Meaning of the Heritability of IQ
}

David S. Moore

Pitzer College

\section{Recommended Citation}

Moore, David. "A Very Little Bit of Knowledge: Re-Evaluating the Meaning of the Heritability of IQ." Human Development 49.6 (2006): 347-353. Print.

This Article - postprint is brought to you for free and open access by the Pitzer Faculty Scholarship at Scholarship @ Claremont. It has been accepted for inclusion in Pitzer Faculty Publications and Research by an authorized administrator of Scholarship @ Claremont. For more information, please contact scholarship@cuc.claremont.edu. 
Running head: Heritability and IQ

The content of this open-access post-print article is the same as that contained in the published article with the following reference:

Moore, D. S. (2006). A very little bit of knowledge: Re-evaluating the meaning of the heritability of IQ. Human Development, 49, 347 - 353.

\author{
A very little bit of knowledge: \\ Re-evaluating the meaning of the heritability of IQ \\ David S. Moore \\ Pitzer College \& Claremont Graduate School \\ Commentary on "A Critical Analysis of IQ Studies of Adopted Children" by Ken \\ Richardson and Sarah Norgate
}

April 20, 2006

David Moore:

Email: dmoore@pitzer.edu

Address: Pitzer College, Claremont, CA 91711, USA.

Phone: 909-607-1648

Fax: 909-621-8481

5 key words: Heritability, Nature and Nurture, accounting for variation, adoption, IQ 
A very little bit of knowledge:

Re-evaluating the meaning of the heritability of IQ

Richardson and Norgate (this volume) have argued that two unwarranted assumptions underlie many of the conclusions drawn by adoption-study researchers, namely that genetic and environmental influences on phenotypic variation are additive, and that adoption studies approximate a simple randomized-effects design in which genetic and environmental influences on variance do not contaminate one another. As they note, this issue is important because the primary conclusions of such studies—-that genetic variation accounts for a significant proportion of variation in psychological characteristics such as IQ— have been widely accepted (Maccoby, 2001; Nuffield Council on Bioethics, 2002; Turkheimer, 2005).

To address the inappropriateness of the assumption of additivity, Richardson and Norgate refer to several works that support the ascendant view that biological and psychological characteristics are constructed during development when genes interact with local environmental factors that can be influenced by the broader environment; however, it is worth noting that the literature in developmental biology is replete with findings that support this view, so much so that the earlier view that some genes are able to independently cause or contribute to developmental outcomes is effectively indefensible (Coen, 1999; Edelman, 1988; Keller, 2000; Gottlieb, 1998; Jablonka \& Lamb, 2005; Lewontin, 2000; Lickliter \& Honeycutt, 2003; Michel \& Moore, 1995; Moore, 2002; Robert, 2004; Schaffner, 1998). Because gene-environment interactions are now understood to drive the development of all of our characteristics, the assumption of additivity is never warranted (Nijhout, 2002; Robert, 2000). Likewise, after reviewing 
the relevant data, Richardson and Norgate conclude that the assumption that adopted children's genes are uncorrelated with their adoptive developmental environments is probably unwarranted in many cases as well.

There is, however, a deeper assumption underlying adoption studies that is often not acknowledged by either adoption study researchers or their critics, and it is an assumption that is at least as important as the two considered by Richardson and Norgate: the assumption that the heritability statistics generated by adoption studies are informative about something of consequence. Although Richardson and Norgate's paper presents several valid criticisms of adoption studies of IQ that lead them to suggest a "radical reappraisal" of such studies, a reappraisal even more radical than the one they suggest might, in fact, be warranted.

Heritability statistics were developed by Francis Galton and Karl Pearson near the dawn of the $20^{\text {th }}$ century (Kevles, 1995), when knowledge about biological mechanisms was so lacking that the idea that nature and nurture represent separate contributors to human characteristics seemed reasonable. In such a context, the finding that, say, $80 \%$ of the variation in a trait could be accounted for by variation in genetic factors was interesting, because it seemed to suggest that the trait in question was more influenced by biological factors than environmental factors. In addition, such findings seemed to suggest that if genetic variation could account for $80 \%$ of the variation in trait $\mathrm{X}$ but only $30 \%$ of the variation in trait $\mathrm{Y}$, then the development of trait $\mathrm{X}$ was less influenced by a person's experiences than was the development of trait Y.

Now, however, we understand that all of our characteristics - be they biological or psychological — are equally influenced by genetic and non-genetic factors. For 
example, after a detailed review of how genes contribute to behavior in the roundworm C. elegans — "the simplest model organism that possesses a working nervous system" (p. 213 - 215) - Schaffner (1998) wrote that although our understanding of how genes contribute to behaviors in this extremely well studied organism is arguably richer than is our understanding of these processes in any other organism, it remains the case that:

"No C. elegans investigator ever thinks genes act alone- they all recognize the need for the cellular and extracellular supporting environments, and also look for environmental effects on the organism and on the genes. Naked DNA (or RNA) is not sufficient to produce interesting biological traits...thus, causally, genes have parity with other molecules as severally necessary and jointly sufficient conditions (to produce traits)" (p. 234).

For the same reasons, Gray (1992) concluded that "it is not possible to assign causal primacy nor to dichotomise developmental causation into internal and external components." Moreover, because adoption and twin studies that seek to account for trait variation in terms of genetic and environmental variation are always essentially correlational, they reveal nothing about what causes the appearance of the traits. And yet many psychologists continue to compute heritability statistics without questioning what exactly it is that they reveal to us. Unfortunately, careful consideration of these statistics suggests that they might not be applicable in any meaningful way, and so consequently, are uninteresting at best and misleading at worst (Block, 1995; Wahlsten, 1990).

A simple analogy can help reveal how little an analysis of variation can tell us about causation. ${ }^{1}$ At the North Pole, where it is normally always cold enough to snow, 
variation in snowfall across days is exclusively a function of the relative humidity in the atmosphere. ${ }^{2}$ Likewise, if we imagine a mountainous region where it happens to always be humid enough to produce precipitation, variation in snowfall will be completely accounted for by the variations in temperature that are associated with different altitudes. Thus, even though we know that the formation of snow requires both a high level of humidity and a low temperature, analyses of variation in these cases would indicate that temperature accounts for none of the variation in snowfall at the North Pole and that humidity accounts for none of the variation in snowfall in the mountainous rainforest.

The point of this analogy is that the results of analyses of variation depend completely on the background circumstances under which the studies are conducted. If factors $\mathrm{A}$ and $\mathrm{Z}$ are necessary and sufficient to produce a given outcome, then if factor $\mathrm{A}$ does not vary in a particular context, factor $\mathrm{Z}$ accounts for $100 \%$ of the variation in the outcome in that context; but if, in a different context, factor $\mathrm{Z}$ does not vary, then in this context, factor $\mathrm{Z}$ accounts for $0 \%$ of the variation in the outcome. More generally, the amount of variation that can be accounted for by one factor always depends on the amount of variation in the other factor. ${ }^{3}$ But if a factor that makes a causal contribution to an outcome can account for anywhere from $0 \%$ to $100 \%$ of the variation in that outcome (depending on the context), then clearly, statistics that account for variation tell us nothing at all about the factor's causal contribution to the outcome.

Of course, some adoption study researchers claim to understand the limitations of heritability statistics, but a sizeable proportion of those who encounter these statisticsincluding both students and professionals — is nonetheless likely to wind up confused about what the statistics mean (and the extent to which they are inapplicable in most 
contexts), and ultimately arrive at the erroneous conclusion that highly heritable traits are more influenced by genetic factors than are those traits that are not heritable at all. In fact, environmental factors influence the development of highly heritable traits just as much as they influence the development of non-heritable traits (consider, for example, how nutritional factors influence highly heritable characteristics like height), and genetic factors influence the development of non-heritable traits just as much as they influence the development of highly heritable traits. We can see this latter point easily by considering the fact that having 5 fingers on each of our hands is not a particularly heritable characteristic (because most finger-number variations in human populations are attributable not to genetic variation, but to variation in experiences, such as differential experience of industrial accidents); nonetheless, it is quite obvious that genetic factors play a role in determining the number of fingers we have on each of our hands (Block, 1995).

Obviously, then, heritability statistics are not useful in the way that we intuitively expect, but can they serve some purpose? Although Richardson and Norgate do not address this question in their paper, the issue is important if there is even a remote possibility that the answer is "no." In fact, a meteorologist at the North Pole can rely on measures of humidity alone to predict snowfall, because information about how variation in one factor contributes to variation in an outcome can be used to predict outcomes in circumstances identical to those in which the original information was generated. But using information from adoption studies of IQ in this way is not possible, because estimates of the heritability of IQ will range from 0.00 to 1.00 as a function of variability (across testing circumstances) in the environmental factors that contribute to IQ. The 
problem is that our understanding of the factors that contribute to the development of human traits in general — and to IQ in particular - is currently so deficient that we typically do not know if the environmental factors important in the development of a particular trait are stable across testing situations, vary somewhat across those situations, or vary wildly across those situations.

As a result, it is not clear how heritability statistics can be properly applied, or even if they can be of any use to us whatsoever. Well-trained psychologists generally understand that population-level information like this can never be used to make predictions about individual development, but the problems outlined here suggest that such information cannot even be used to make population-level predictions in circumstances that vary in any way from those in which the original analysis-of-variation study was conducted. Even if a population of individuals were to develop in a range of environments believed to be the same as that in which a particular analysis-of-variation study was conducted, the results of that study would not allow us to correctly predict developmental outcomes in the new range of environments, because the environmental factors that the researchers originally focused on — and controlled for - might not be the relevant environmental factors at all; instead, the crucial environmental factors might remain unmeasured, and consequently, variability of those factors across the new range of environments could easily be very different than the variability of those factors across the environments sampled in the original study.

One response to this argument might be to measure all of those environmental factors that are likely to affect the development of a trait. However, in the past decade, developmentalists have discovered that it is often not at all obvious prior to 
developmental analysis which environmental factors might make important contributions to the development of specific traits. For example, Gottlieb $(1981,1991)$ has found that a newborn mallard duckling's normal attraction to the "assembly call" of its mother depends not on hearing examples of that call prior to hatching, but on hearing its own embryonic vocalizations, even though the vocalizations of mallard embryos sound almost nothing at all like the calls of mature mallard ducks. Likewise, Masataka (1993) has demonstrated that the fear of snakes that is normally observed in all wild squirrel monkeys - and which was previously thought to be innate - can actually develop not as a result of experience with snakes, but as a nonobvious result of experience with insects. Because the development of behavioral/psychological characteristics can be influenced by experiential factors in ways that are unpredictable from casual observation, we cannot hope to happen to measure - through sheer lucky guesswork - the environmental factors that contribute importantly to the development of those characteristics; we first need to understand the mechanisms by which those traits develop. As a result, rather than spending countless man-hours analyzing how sources of variation in twin and adoption studies account for variations in outcomes, our time and energy would be better spent exploring what causes those outcomes in the first place.

Some theorists might still hope to argue that analysis-of-variation studies can at least provide us with preliminary information about which of our traits are influenced by genetic factors and which are not, but to make such an argument would be to ignore the fundamental conclusion that developmental psychobiologists had reached by the end of the $20^{\text {th }}$ century; that is that all human characteristics are influenced by genetic factors (Rutter, 2002). If a particular characteristic appears not to be heritable at all, that could 
simply mean that the genetic factors that contribute to the development of that characteristic are relatively constant across human populations (as is the case with the genetic factors that help specify the number of fingers on our hands); it need not mean that such unvarying factors are unimportant or do not affect the appearance of the trait. Just because the environments in which fish develop are invariably watery does not mean that their watery environment can be ignored when we consider why fish have the characteristics they do.

In response, researchers who believe in the value of heritability estimates might counter that they are unconcerned with causal factors that are common to all members of a population; they are interested in the factors that account for differences between individuals (Plomin, 1994), so they can ignore factors that are held constant across all of those individuals. The problem with this claim is the fact that individuals are never the unit of analysis in studies of this sort. Instead, such studies proceed by examining variation in a characteristic across a population, and as we have seen, the numbers generated in such studies change as a function of the amount of variation present in each of the (potentially unmeasured) factors that influence the development of the characteristic. How effectively one factor accounts for differences between individuals is always a function of how much other causal factors vary across the population being studied.

What, then, do we learn when we calculate heritability statistics? Calculating the heritability of IQ does not tell us what causes an individual to have a particular IQ. Nor does it tell us if genetic factors contribute to IQ (we already know they do) or how important genetic or environmental influences are on IQ. In fact, behavior geneticists 
themselves have long acknowledged that heritability statistics do nothing to illuminate the development of traits in individuals. In addition, I have argued elsewhere that heritability statistics do not tell us how likely it is that people's characteristics will be inherited by their children (Moore, 2002). Thus, although heritability statistics do tell us how much of the variation in IQ can be accounted for by genetic factors when development occurs in an exquisitely specific range of environments, any sense that this information is meaningful disappears when we realize that the magnitude of any heritability statistic reflects the extent of variation in unidentified non-genetic factors that contribute to the development of the trait in question. Consequently, because we cannot assess the variability (across our testing environments) of all of the yet-to-be-identified non-genetic factors that influence IQ, estimates of the heritability of IQ are effectively uninterpretable and unable to be applied in any appropriate way.

Richardson and Norgate do not focus in their paper on these concerns about the use and interpretability of heritability statistics; however, they do identify several factors that can explain why the data generated in recent adoption studies of IQ have been consistent with data collected in other adoption and twin studies. These factorsincluding selective placement, the effects of adoptive status itself, the effects of the prenatal environment on development, etc.- - might, in fact, be helpful in explaining the pattern of correlations traditionally found in adoption studies. When there is a good 'fit' of an additive model to an adoption-study data set, it is tempting to conclude that the model is able to explain the data; however in the current case, such a fit cannot be taken to support arguments for additive effects, because as Richardson and Norgate note, the theoretical foundations of these arguments have collapsed in the face of evidence from 
molecular biology. Consequently, other explanations for the fit of additive models to adoption-study data must be sought. The several factors that Richardson and Norgate have identified in their paper can help to explain these correspondences.

Richardson and Norgate's arguments undermine traditional interpretations of twin study data by highlighting various flaws in the logic and execution of such studies; the effects of such flaws likely contribute to the patterns of correlations usually reported in adoption studies. However, it should be stressed that this does not mean that a better understanding of these issues will allow adoption studies to be executed in a "clean" way that will generate useful information. Instead, as Richardson and Norgate note, "the evidence of interactive sources of variance from molecular genetic and other research is now sufficiently strong as to doubt whether adoption studies can in principle answer the kinds of questions at issue." Ultimately, because adoption studies do not entail the purposeful manipulation of either specific genes or specific environmental factors, such studies will always be merely correlational, and so unable to generate satisfying understandings of the factors and processes that contribute to the development of intelligence.

Richardson and Norgate's concerns about the interpretation of adoption-study data are warranted, and the arguments they have presented are convincing. However, there is a deeper problem associated with adoption study methodologies, namely the use of an analysis-of-variation approach instead of an analysis-of-causation approach. Richardson \& Norgate's paper does not address this problem, but it may very well represent the bulk of the iceberg. 


\section{References}

Block, N. (1995). How heritability misleads about race. Cognition, 56, 199 - 128.

Coen, E. (1999). The art of genes: How organisms make themselves. New York: Oxford University Press.

Edelman, G.M. (1988). Topobiology: An introduction to molecular embryology. New York: Basic Books.

Gottlieb, G. (1981). Roles of early experience in species-specific perceptual development. In R.N. Aslin, J.R. Alberts,. and M.R. Petersen (Eds.), Development of perception: Psychobiological perspectives. Vol. 1, Audition, somatic perception, and the chemical senses. New York: Academic Press.

Gottlieb, G. (1991). Experiential canalization of behavioral development: Results. Developmental Psychology, 27, 35 - 39.

Gottlieb, G. (1998). Normally occurring environmental and behavioral influences on gene activity: From central dogma to probabilistic epigenesis. Psychological Review, 105, 792 $-802$.

Gray R. (1992). Death of the gene: Developmental systems strike back. In P. E.Griffiths (Ed.). Trees of Life. Dordrecht: Kluwer.

Jablonka, E., \& Lamb, M. J. (2005). Evolution in four dimensions: Genetic, epigenetic, behavioral, and symbolic variation in the history of life. Cambridge, MA: MIT Press.

Keller, E.F. (2000). The century of the gene. Cambridge, MA: Harvard University Press.

Kevles, D. J. (1995). In the name of eugenics: Genetics and the uses of human heredity. Cambridge, MA: Harvard University Press. 
Lewontin, R. (2000). The triple helix: Gene, organism, and environment. Cambridge, MA: Harvard University Press.

Lickliter, R., \& Honeycutt, H. (2003). Developmental dynamics: Toward a biologically plausible evolutionary psychology. Psychological Bulletin, 129, $819-835$.

Maccoby, E. (2001). Parenting and its effects on children: Misreading behavior genetic evidence. Annual Review of Psychology, 51, $1-28$.

Masataka, N. (1993). Effects of experience with live insects on the development of fear of snakes in squirrel monkeys, Saimiri sciureus. Animal Behaviour, 46, 741 - 746.

Michel, G.F., \& Moore, C.L. (1995). Developmental psychobiology: An interdisciplinary science. Cambridge, MA: MIT Press.

Moore, D.S. (2002). The dependent gene: The fallacy of nature vs. nurture. New York: W.H. Freeman.

Nijhout, H. F. (2002). The nature of robustness in development. Bioessays, 24, $553-563$.

Nuffield Council on Bioethics (2002). Genetics and human behavior: The ethical context. London: Nuffield Council on Bioethics.

Plomin, R. (1994). Genetics and experience: The interplay between nature and nurture. Thousand Oaks, CA: Sage Publications.

Richardson, K., \& Norgate, S.H. (2006). Origins of IQ correlations in studies of adopted children. Human Development, this volume.

Robert, J.S. (2000). Schizophrenia epigenesis? Theoretical medicine and bioethics, 21, 191 215.

Robert, J.S. (2004). Embryology, epigenesis, and evolution: Taking development seriously. Cambridge, U.K.: Cambridge University Press. 
Rutter, M. (2002). Nature, nurture, and development: From evangelism through science toward policy and practice. Child Development, 73, $1-21$.

Schaffner, K.F. (1998). Genes, behavior, and developmental emergentism: One process, indivisible? Philosophy of Science, 65, $209-252$.

Turkheimer, E. (2005). Spinach and ice cream: Why social science is so difficult. In L.F. DiLalla (Ed.), Behavior genetics principles: Perspectives in development, personality and psychopathology. Washington D.C.: American Psychological Association.

Wahlsten, D. (1990). Insensitivity of the analysis of variance to heredity-environment interaction. Behavioral and Brain Sciences, 13, 109 - 161. 
Author Note

I gratefully acknowledge the assistance of Elsa Burt, Christopher B. Braun, J. Steven Reznick, Mita Banerjee, and Robert Lickliter, whose criticisms of an earlier draft of this paper contributed helpfully to its final form.

Correspondence concerning this article can be sent via e-mail to dmoore@pitzer.edu or via traditional mail to David Moore, at Pitzer College, Claremont, CA 91711, USA. 


\section{Footnotes}

${ }^{1}$ Note that the broad approach that I am calling an analysis of variation is conceptually distinct from the similarly named statistical test of significance known as an analysis of variance.

${ }^{2}$ For the purposes of this discussion, I will ignore how factors like atmospheric pressure and dynamic stability of the troposphere are related to precipitation of snow, neither of which bears on the points I am making.

${ }^{3}$ This is why we ought not expect to find similar heritabilities of IQ in, say, North and South America; as Block (1995) has noted, there is little reason to think that the variation in the environmental factors that contribute to intellectual development would be equivalent in such disparate contexts. 